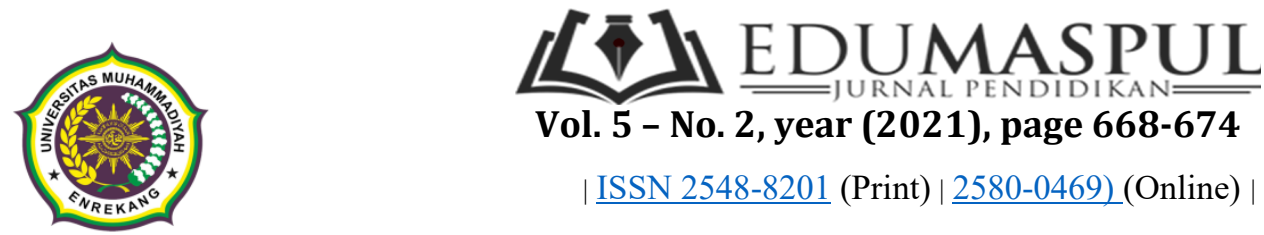

\title{
Pengaruh Video Animasi terhadap Pemahaman Konsep Segitiga Siswa Kelas IV di SDN Gentramasekdas
}

\author{
Thya Twozia \\ * Corresponding Author. E-mail: thyatwozia22@ummi.ac.id
}

Receive: 13/05/2021

Accepted: 23/08/2021

Published: 01/10/2021

\begin{abstract}
Abstrak
Penelitian ini bertujuan untuk mengetahui adakah pengaruh dari media video animasi terhadap pemahaman konsep segitiga siswa kelas IV di SDN Gentramasekdas terhadap 32 siswa. Metode penelitian ini menggunakan eksperimen yang menggunakan bentuk penelitian Quasi Experimental Desaign. dengan tujuan untuk mengetahui adakah efektifitas dari media video animasi terhadap pemahaman konsep segitiga siswa kelas IV di SDN Gentramasekdas. Populasi dalam penelitian ini yaitu seluruh kelas IV (empat) dengan mengambil sampel dua kelompok belajar (kelompok belajar eksperimen dan kelompok belajar kontrol) melalui teknik random sampling. Data penelitian didapat melalui kegiatan pre-test (kemampuan awal siswa kedua kelompok) dan post-test (kemampuan akhir siswa kedua kelompok). Data dianalisis dengan menggunakan menggunakan uji t dua berpasangan (paired-sample t test). Lalu untuk mengetahui adakah pengaruh penggunaan media video pembelajaran matematika terhadap pemahaman konsep siswa dapat dilihat dari hasil data posttest kedua kelompok yang dianalisis menggunakan uji t dua sampel independen. Hasil analisis data menunjukan bahwa penggunaan media video animasi memberikan pengaruh terhadap pemahaman konsep segitiga siswa kelas IV yang pada akhirnya akan mempengaruhi prestasi belajar siswa secara keseluruhan. Sehingga $\mathrm{H}_{1}$ diterima dan $\mathrm{H}_{0}$ ditolak dengan penjelasan bahwa media video animasi memberikan pengaruh terhadap pemahaman konsep segitiga siswa SD.
\end{abstract}

Kata Kunci: Video Animasi, Pemahaman Konsep, Segitiga

\section{Abstract (English-Indonesia)}

This study aims to determine the effectiveness of the animated video media on the understanding of the triangle concept of fourth grade students at SDN Gentramasekdas to 32 students. This research method uses an experiment that uses a Quasi Experimental Design research form. with the aim of knowing whether there is an effectiveness of animated video media on the understanding of the triangle concept of fourth grade students at SDN Gentramasekdas. The population in this study is the entire class IV (four) by taking samples of two study groups (experimental study group and control study group) through random sampling technique. The research data was obtained through pre-test (initial ability of students in both groups) and post-test (final ability of students in both groups). Data were analyzed using paired-sample t test. Then to find out whether there is an effect of using video media for mathematics learning on students' conceptual understanding, it can be seen from the results of the posttest data of the two groups which were analyzed using two independent sample t-tests. The results of data analysis show that the use of animated video media has an influence on the understanding of the triangle concept of fourth grade students which in turn will affect overall student achievement. So that $\mathrm{H}_{1}$ is accepted and $\mathrm{H}_{0}$ is rejected with the explanation that animated video media has an influence on understanding the triangle concept of elementary school students.

Keywords: Animation Video, Understanding Mathematical Concepts, Triangles 


\section{Pendahuluan}

Pendidikan merupakan kebutuhan setiap individu manusia. Sekolah Dasar (SD) merupakan jenjang pendidikan formal pertama yang diselenggarakan dengan tujuan meletakkan dasar kecerdasan, pengetahuan, kepribadian, akhlak mulia, dan keterampilan untuk hidup mandiri. Pelajaran matematika memiliki peranan yang sangat penting dalam proses peningkatan kualitas sumber daya manusia. Sebagaimana dikemukakan oleh Prasetia (2016: 256) bahwa "Matematika merupakan ilmu universal yang mendasari perkembangan dunia modern saat ini, matematika juga memiliki peran yang cukup 'sentral' di dalam berbagai disiplin ilmu dan juga dapat memajukan daya pikir manusia". Salah satu cara meningkatkan kualitas sumber daya manusia yaitu dengan memperbaiki proses pembelajaran di sekolah. Dimana perkembangan pesat di berbagai bidang informasi dan komunikasi pada saat ini didasari oleh perkembangan ilmu matematika itu sendiri.

Dalam Peraturan Menteri Pendidikan Nasional (2006) Nomor 22 tentang Standar Isi tujuan pembelajaran matematika agar siswa memiliki kemampuan untuk memahami konsep matematika, menggunakan penalaran pada pola dan sifat dimana siswa dapat menyelesaikan pemecahan masalah, sehingga siswa bisa mengkomunikasikan kembali, menjelaskan keterkaitan konsep, gagasan dan simbol secara akurat dan tepat dalam penyelesaiannya. Sehingga mendapatkan hasil belajar yang di harapkan, dapat melatih siswa memiliki sikap ulet, sikap menghargai kegunaan matematika dalam kehidupan seharihari, baik itu minat, perhatian, rasa ingin tahu, dan percaya diri dalam pemecahan masalah. Berdasarkan tujuan pembelajaran matematika tersebut, pemahaman konsep sangatlah diperlukan agar mencapai hasil pembelajaran matematika sesuai dengan apa yang diharapkan.

Fakta yang terjadi dilapangan masih banyak siswa yang masih menganggap pembelajaran matematika adalah pembelajaran yang tidak menyenangkan dan sulit untuk dipelajari bahkan untuk saat ini alokasi waktu pembelajaran berkurang karena pandemi saat ini. Hal ini terbukti dengan hasil Ulangan Tengah Semester (UTS) genap tahun pelajaran 2020/2021, dimana hasil UTS tersebut menunjukan dari 50 siswa yang ada di kelas IV nilai rata-rata yang diperoleh belum mencapai nilai Kriteria Ketuntasan Minimal (KKM) yang telah ditetapkan yaitu 75 sehingga dari jumlah siswa yang mengikuti UTS hanya beberapa siswa yang memenuhi nilai KKM. Dalam kelas IV terdapat dua rombel kelas yang mana kelas IVA dengan jumlah siswa 24 memperoleh nilai rata-rata hasil UTS sebesar 61,87 sedangkan kelas IVB dengan jumlah siswa 26 Siswa memperoleh nilai rata-rata hasil UTS sebesar 66,87 sehingga dari keseluruhan siswa kelas IV rata-rata nilai hasil UTS sebesar 64,73.

Melihat dari permasalahan tersebut, maka diperlukannya suatu pemecahan masalah untuk membantu proses pembelajaran matematika pada kelas IV yaitu dengan menggunakan video animasi sebagai media pendamping untuk kegiatan pembelajaran. menurut pendapat Muhtarom, et al. (2020) yang memaparkan bahwa "Video pembelajaran merupakan media yang menyajikan informasi yang terdiri dari teks, suara, animasi". Penggunaan media video animasi ini merupakan sebuah inovasi yang dapat membantu siswa dalam memahami materi, membantu siswa belajar karena pembelajaran dapat diulang dengan memutar kembali video animasi sehingga melatih siswa untuk belajar mandiri dan dapat memotivasi semangat siswa untuk belajar dengan materi ajar yang dibuat secara tersusun, menarik, sehingga dapat meningkatkan pemahaman siswa dalam

pembelajaran. Pemanfaatan video animasi yang digunakan sebagai media pembelajaran juga dapat membantu guru untuk lebih produktif, kreatif dan inovatif dalam menciptakan proses pembelajaran yang menyenangkan serta dapat menjadi penyampai materi yang efektif sehingga materi tersampaikan dengan baik. 
Pemahaman konsep yang dipaparkan oleh Pradipta (2018: 67) memiliki artian sebagai kompetensi untuk siswa dalam memahami sesuatu serta menangkap makna dari suatu yang telah diterima dalam pikiran. Penjelasan tersebut selaras dengan pendapat Susanto (2016: 6) bahwa pemaham konsep merupakan salah satu dari kelompok hasil belajar yang Pemahaman konsep ini dilihat dari hasil belajar siswa yang erat hubungannya dengan tujuan dari pembelajaran itu sendiri. Tujuan pembelajaran biasanya sudah direncanakan sebelum proses pembelajaran berlangsung. Dimana dalam proses pembelajaran di Sekolah Dasar umumnya hasil belajar dari pemahaman konsep dapat dilihat dari evaluasi pembelajaran yang berupa seperti berbagai macam test berbentuk penugasan, ulangan harian, ulangan tengah semester, ulangan semester maupun ulangan kenaikan kelas.

Pemahaman konsep matematika yaitu kemampuan atau kesanggupan untuk menjelaskan suatu hasil dari pemikiran seseorang berupa objek kongkret maupun abstrak dalam materi matematika dengan menggunakan bahasa yang berbeda (Sari, 2018: 38). Untuk kemampuan pemahaman matematis menurut Susanto (2016: 208) dijelakan sebagai suatu proses mental dengan terjadinya adaptasi dan transformasi konsepkonsep dalam pembelajaran matematika yang terorganisasi secara sistematis, logis dan hierarkis dari yang paling sederhana ke hal yang kompleks untuk menguasi materi atau konsep selanjutnya.

Berdasarkan penjelasan di atas dapat penulis simpulkan bahwa pemahaman konsep yaitu sebagai hasil dari proses belajar yang dapat dilihat dari kemampuan seseorang

menjelaskan kembali keterkaitan konsep yang telah dipelajari menggunakan bahasa sendiri. Pemahaman konsep dapat di gunakan untuk proses pemecahan masalah dalam kegiatan pembelajaran matematika melalui latihan soalsoal yang di sesuaikan dengan standar kompetensi inti dan kompetensi dasar yang di tuangkan pada tujuan dari pembelajaran dimana salah satunya yaitu mampu menerapkan konsep-konsep matematika di kehidupan sehari-hari. Dengan demikian upaya untuk mengatasi permasalah yang telah di paparkan diatas, peneliti mengambil seluruh indikator pemahaman konsep matematika menurut Lestari \& Yudhanegara (2018:18) di sekolah dasar dengan materi segitiga. Segitiga termasuk pada salah satu materi bangun datar syang dipelajari di tingkat sekolah dasar. Segitiga adalah bangun datar yang dibatasi oleh tiga buah sisi garis lurus dan mempunyai tiga titik sudut yang jumlah ketiga sudutnya yaitu $180^{\circ}$ (Hobri et al., 2019: 111). Materi bangun datar segitiga yang akan diambil dalam pembahasan pemahaman konsep matematika meliputi pengertian, jenis-jenis segitiga, keliling dan luas segitiga. dengan indikator pemahaman konsep menjelaskan, mengklasifikasikan, menerapkan, mencontohkan, menyajikan dan mengkaitkan ulang konsep yang telah dipelajari.

\section{Metode Penelitian}

Jenis penelitian yang digunakan dalam penelitian ini yaitu dengan metodologi penelitian eksperimen. Menurut Jaksin (2016:1) mengemukakan bahwa penelitian eksperimen diartikan sebagai percobaan untuk mencari hubungan sebab dan akibat antara variabel bebas dan terikat, dimana variabel bebas penelitian sengaja dikendalikan dan dibedakan perlakuan (dimanipulasi). Dimana dengan metode penelitian eksperimen yang akan dilakukan dilapangan menggunakan bentuk penelitian Quasi Experimental Desaign, dengan tujuan untuk mengetahi adakah pengaruh dari media video animasi terhadap pemahaman konsep segitiga siswa kelas IV di SDN Gentramasekdas.

Populasi dalam penelitian ini yaitu 50 siswa kelas IV di SDN Gentramasekdas, dengan jumlah siswa kelas IV-A sebanyak 26 siswa dan jumlah siswa kelas IV-B 24 siswa. Melihat dari situasi pandemi Covid-19 serta hasil wawancara dengan guru kelas IV, pembagian kelas di perkecil menjadi kelompok-kelompok dimana terdapat empat kelompok yang di tentukan sesuai zona wilayah tempat tinggal siswa masing-masing. Sampel yang digunakan dalam penelitian ini menggunakan teknik cluster 
random sampling yang cara pengambilan sampelnya berdasarkan gugus. Dari data populasi penelitian di atas, peneliti mengambil sampel sebanyak dua kelompok zona wilayah yang akan dijadikan sebagai kelompok eksperimen dan kelompok kontrol. Setelah dilakukan random (acak) didapat sampel yaitu kelompok zona wilayah 1 dan kelompok zona wilayah 2 yang masing-masing memiliki 16 siswa.

Data awal penelitian diperoleh dari pelaksanaan pretest yang bertujuan untuk mengetahui kemampuan awal siswa baik itu kelompok eksperimen maupun kelompok kontrol sebelum diberikan perlakuan media video animasi. Dimana hasil dari nilai pretest kelas eksperimen maupun kelas kontrol akan digunakan sebagai hasil data sebelum menggunakan media video animasi. Adapun hasil dari pretest yang telah dilakukan pada kedua kelompok dapat dilihat pada tabel 1 berikut ini:

\section{Tabel 1 Hasil Data Pretest Kelompok Eksperimen dan Kelompok Kontrol Descriptive Statistics}

\begin{tabular}{cc|c|c|c|c} 
& $\mathrm{N}$ & $\begin{array}{c}\text { Mini } \\
\text { mum }\end{array}$ & $\begin{array}{c}\text { Ma } \\
\text { xim } \\
\text { um }\end{array}$ & $\begin{array}{c}\text { Mea } \\
\mathrm{n}\end{array}$ & $\begin{array}{c}\text { Std. } \\
\text { Deviation }\end{array}$ \\
\hline $\begin{array}{c}\text { Pretest } \\
\text { Eksperimen }\end{array}$ & 16 & 24 & 74 & $\begin{array}{c}54,7 \\
5\end{array}$ & 13,950 \\
\hline $\begin{array}{c}\text { Pretest } \\
\text { Kontrol }\end{array}$ & 16 & 36 & 66 & $\begin{array}{c}50,6 \\
3\end{array}$ & 10,475 \\
\hline $\begin{array}{c}\text { Valid N } \\
\text { (listwise) }\end{array}$ & 16 & & & & \\
\hline
\end{tabular}

(Sumber: Analisis Data Penelitian, 2021)

Dilihat dari tabel 1 di atas dapat dijelaskan bahwa rata-rata nilai Pretest untuk kelompok Eksperimen di peroleh nilai 54,75 dengan jumlah siswa yang mengikuti pretest sebanyak 16 siswa. dengan nilai terendahnya yaitu 24 dan nilai tertingginya yaitu 74 . Sedangkan untuk Kelompok kontrol didapatkan nilai rata-rata pretest yaitu 50,63 dengan jumlah siswa yang mengikuti pretest berjumlah 16 siswa. nilai terendah yang didapat yaitu 36 dan nilai tertingginya yaitu 66. Standar deviasi untuk kelompok eksperimen yaitu 13,950 sedangkan untuk kelompok kontrol standar deviasinya yaitu 10,475 .

Analisis data dilanjutkan dengan menguji prasyarat statistika yang diperlukan sebagai dasar dalam pengujian hipotesis, yaitu dengan Uji normalitas dengan menggunakan aplikasi IMB SPSS Statistics 28,0 yaitu uji statistik Kolmogorov-Smirnov dan Shapiro-Wilk dengan nilai Signifikasi (Sig) $>0,05$ yang dapat di simpulkan data tersebut berdistribusi normal dan apabila nilai Signifikasi (Sig) $<0,05$ dapat di simpulkan data tersebut tidak berdistribusi normal. Berikut hasil uji normalitas data penelitian Pretest yang dapat di lihat pada tabel 2 dibawah ini:

\section{Tabel 2 Hasil Uji Normalitas Pretest Kelompok Kontrol dan Kelompok Eksperimen}

\begin{tabular}{|c|c|c|c|c|c|c|c|}
\hline & & Tests & of $\mathrm{No}$ & ormal & & & \\
\hline & & $\begin{array}{r}\text { Kolr } \\
\mathrm{Sn}\end{array}$ & $\begin{array}{l}\text { nogo } \\
\text { nirno }\end{array}$ & $\begin{array}{l}\text { rov- } \\
v^{a}\end{array}$ & Shap & iro- & Vilk \\
\hline & Kelompok & $\begin{array}{l}\text { Stat } \\
\text { istic }\end{array}$ & $\mathrm{df}$ & Sig. & $\begin{array}{c}\text { Statist } \\
\text { ic }\end{array}$ & $\mathrm{df}$ & Sig. \\
\hline $\begin{array}{c}\text { Nila } \\
\text { i }\end{array}$ & $\begin{array}{c}\text { Kelompok } \\
\text { Eksperime } \\
n\end{array}$ & ,155 & 16 &, 200 & ,936 & $\begin{array}{l}1 \\
6\end{array}$ & ,300 \\
\hline $\begin{array}{c}\text { Pret } \\
\text { est }\end{array}$ & $\begin{array}{c}\text { Kelompok } \\
\text { Kontrol }\end{array}$ &, 171 & 16 &, 200 & ,922 & $\begin{array}{l}1 \\
6 \\
\end{array}$ &, 180 \\
\hline
\end{tabular}

*. This is a lower bound of the true significance. a. Lilliefors Significance Correction

(Sumber: Analisis Data Penelitian 2021)

Melihat tabel 2 diatas, hasil dari uji normalitas pretest kelompok eksperimen memperoleh nilai sig $=0,200$ menggunakan uji Kolmogorov-Smirnov dan memperoleh nilai sig $=0,300$ dengan menggunakan uji Shapiro-Wilk. Sedangkan untuk kelompok Kontrol memperoleh nilai sig $=0,200$ menggunakan uji Kolmogorov-Smirnov dan memperoleh nilai sig $=0,180$ dengan menggunakan uji Shapiro-Wilk. Karena dari kedua uji Kolmogorov-Smirnov dan Uji Shapiro-Wilk memiliki nilai sig. $>0,05$ baik itu kelompok Eksperimen maupun kelompok Kontrol maka Hipotesis yang digunakan yaitu $\mathrm{H}_{0}$ diterima yang dapat di simpulkan bahwa data nilai pretest kelompok eksperimen maupun 
kelompok kontrol berasal dari data berdistribusi normal.

Dilanjutkan dengan Uji homogenitas dilakukan agar dapat menunjukan subjek populasi, apakah bersifat homogen atau heterogen dengan tujuan agar sampel yang diambil benar-benar respresentatif atau dapat mewakili dari seluruh populasi (Jaksin, 2016: 256). Dengan dilakukan uji homogenitas pada data pretest penulis mengetahui apakah data yang telah di peroleh bervarians homogen atau tidak homogen (heterogen). Dimana dasar dari pengambilan keputusan untuk uji homogenitas menggunakan Hipotesis sebagai berikut:

$\mathrm{H}_{0}$ : Hasil nilai Pretest berasal dari populasi bervariansi homogen

$\mathrm{H}_{1}$ : Hasil nilai Pretest berasal dari populasi tidak bervariansi homogen

Uji Homogenitas dalam penelitian ini menggunakan aplikasi IMB SPSS Statistics 28,0 dengan dasar pengambilan keputusan yaitu apabila nilai Signifikasi (Sig) pada based on mean $>0,05$ yang dapat di simpulkan data tersebut bervariansi homogen dan dan apabila nilai Signifikasi (Sig) pada based on mean < 0,05 dapat di simpulkan data tersebut tidak bervariansi homogen. Berikut hasil uji homogenitas data penelitian Pretest yang dapat di lihat pada tabel 3 dibawah ini:

Tabel 3 Hasil Uji Homogenitas Pretest

Kelompok Kontrol dan Kelompok Eksperimen

Test of Homogeneity of Variance

\begin{tabular}{cc|c|c|c} 
& $\begin{array}{c}\text { Levene } \\
\text { Statisti } \\
\text { c }\end{array}$ & $\begin{array}{c}\text { df } \\
1\end{array}$ & df2 & Sig. \\
\hline $\begin{array}{c}\text { Based on } \\
\text { Mean }\end{array}$ & 1,085 & 1 & 30 &, 306 \\
\hline $\begin{array}{c}\text { Based on } \\
\text { Nilai }\end{array}$ &, 530 & 1 & 30 &, 472 \\
\hline $\begin{array}{c}\text { Median } \\
\text { Bretes } \\
\mathrm{t} \quad \begin{array}{c}\text { Bedian and on } \\
\text { with } \\
\text { adjusted df }\end{array}\end{array}$ &, 530 & 1 & 22,09 &, 474 \\
$\begin{array}{c}\text { Based on } \\
\text { trimmed } \\
\text { mean }\end{array}$ &, 980 & 1 & 30 &, 330 \\
\hline
\end{tabular}

(sumber: Analisis Data Penelitian 2021)
Hasil uji homogenitas berdasarkan pada tabel 3 di atas dapat dijelaskan bahwa dari nilai Sig pada based on mean dapa nilai pretest kelompok eksperimen dan kelompok kontrol yaitu 0,306 yang mana dapat di simpulkan bahwa data nilai pretest dengan perolehan sig tersebut berkeputusan data uji homogenitas bervariansi homogen dengan hipotesis bahaw $\mathrm{H}_{0}$ diterima dimana kelas eksperimen dan kelas kontrol berasal dari populasi data yang bervariansi homogen.

\section{Hasil dan Pembahasan}

Hasil penelitian menunjukan bahwa terdapat pengaruh penggunaan media video animasi terhadap pemahaman konsep segitiga siswa, hal tersebut dapat dilihat dari Perbandingan data nilai hasil posttest dalam penelitian yang menggunakan uji $t$ dua sampel independen pada kedua kelompok, dengan tujuan untuk mengetahui apakah data nilai posttest kelompok kontrol dan kelompok eksperimen tersebut memiliki kemampuan awal yang sama atau tidak sebelum diberikan perlakuan. Dasar pengambilan keputusan yang digunakan yaitu dengan menggunakan pengujian hipotesis uji $t$ dua sampel independen sebagai berikut:

- $\mathrm{H}_{0}: \mu_{1}=\mu_{2}$ yaitu kelompok eksperimen dan kelompok kontrol memiliki nilai rata-rata yang sama

- $\mathrm{H}_{1}: \mu_{1} \neq \mu_{2}$ yaitu kelompok eksperimen dan kelompok kontrol memiliki nilai rata-rata yang tidak sama

Uji T Dua Sampel Independen dalam analisis data penelitian ini menggunakan aplikasi IMB SPSS Statistics 28.0 dengan taraf Signifikasi (Sig) yaitu $=0,05$. Apabila nilai $\mathrm{Sig}<0,05$ maka terdapat perbedaan kemampuan awal antara dua kelompok dan apabila nilai Sig $>0,05$ maka kedua kelompok memiliki kemampuan awal yang sama. Berikut hasil perbandingan data nilai penelitian posttest yang dapat di lihat pada tabel 4.9 dibawah ini:

Tabel 4 Hasil Perbandingan posttest (Uji T Dua Sampel Independen)

\begin{tabular}{|l|c|c|c|c|}
\hline No. & Sampel & $\begin{array}{c}\text { Rata- } \\
\text { Rata } \\
\text { Nilai }\end{array}$ & $\begin{array}{c}\text { Nilai } \\
\text { Sig }\end{array}$ & Ket \\
\hline
\end{tabular}




\begin{tabular}{|l|l|l|c|c|}
\hline & & $\begin{array}{c}\text { (Two- } \\
\text { Sided } \\
\text { P) }\end{array}$ & \\
\hline 1 & $\begin{array}{l}\text { Kelompok } \\
\text { Eksperimen }\end{array}$ & 85.38 & \multirow{2}{*}{0,001} & $\begin{array}{c}\mathrm{H}_{1} \\
\text { diterima }\end{array}$ \\
\cline { 1 - 3 } 2 & $\begin{array}{l}\text { Kelompok } \\
\text { Kontrol }\end{array}$ & 64,00 & & \\
\hline
\end{tabular}

(Sumber: Analisis Data Penelitian 2021)

Hasil perbandingan posttest pada tabel 4 di atas dapat di jelaskan bahwa hasil uji $\mathrm{t}$ dua sampel independen dari dua kelompok memiliki nilai Sig. $=0,001$. Oleh karena itu $\mathrm{H}_{1}$ diterima dan $\mathrm{H}_{0}$ ditolak dan dapat disimpulkan bahwa kedua kelompok memiliki kemampuan pemahaman konsep segitiga yang berbeda secara signifikan. Perbandingan nilai antara dua kelompok dapat dilihat pada diagram batang 1 dibawah ini.

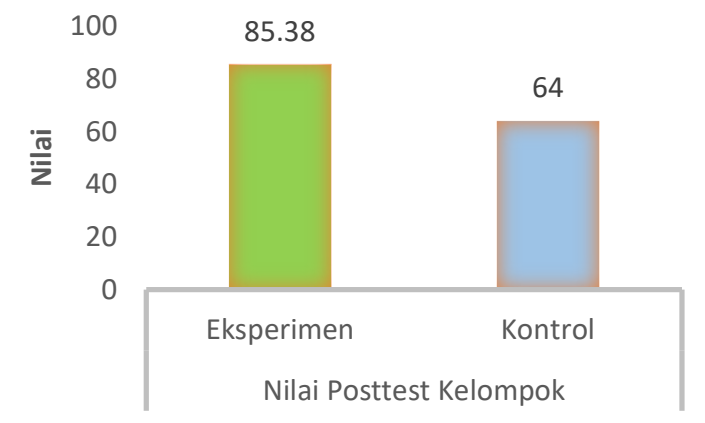

\section{Diagram 1 Perbandingan Nilai Posttest}

Melihat dari diagram $4.3 \mathrm{di}$ atas menunjukan bahwa terdapat perbedaan diantaran nilai posttest kelompok eksperimen dengan nilai posttest kelompok kontrol. Untuk kelompok eksperimen memperoleh nilai ratarata posttest yaitu sebesar 85,38, sedangkan untuk kelompok kontrol memperoleh skor nilai 64 yang memiliki selisih nilai 21,38 diantara kedua kelompok. Sedangkan untuk perbedaan hasil nilai rata-rata posttest kedua kelompok yaitu sebesar 10,69\%. Maka dari hasil penelitian yang di lakukan dapat penulis simpulkan bahwa dengan proses pembelajaran menggunakan media bantu video animasi memberikan pengaruh terhadap pemahaman konsep segitiga siswa.

Dilanjutkan dengan Uji hipotesis yang bertujuan untuk membuktikan kebenaran dari hasil penelitian ini, dimana dalam pengujian ini dilakukan dengan bantuan applikasi SPSS Statistics 28,0 menggunakan uji t dua sampel independen. Adapun kriteria uji hipotesis yang disediakan sebelumnya yaitu H0 ditolak (tidak terdapat pengaruh video animasi terhadap pemahaman konsep segitiga siswa kelas IV SDN Gentramasekdas) apabila nilai Sig. $>0,05$ dan H1 diterima (terdapat pengaruh video animasi terhadap pemahaman konsep segitiga siswa kelas IV SDN Gentramasekdas) apabila nilai Sig. $<0,05$. Hasil Uji hipotesis pada penelitian ini dapat dilihat pada tabel 4.9 Di bawah ini.

Tabel. 5 Hasil Uji Hipotesis Penelitian

\begin{tabular}{|l|l|l|c|c|}
\hline No. & Sampel & $\begin{array}{c}\text { Rata- } \\
\text { Rata } \\
\text { Nilai }\end{array}$ & $\begin{array}{c}\text { Nilai } \\
\text { Sig } \\
\text { (Two- } \\
\text { Sided } \\
\text { P) }\end{array}$ & Ket \\
\hline 1 & $\begin{array}{l}\text { Kelompok } \\
\text { Eksperimen }\end{array}$ & 85.38 & 0,001 & $\begin{array}{c}\mathrm{H}_{1} \\
\text { diterima }\end{array}$ \\
\hline 2 & $\begin{array}{l}\text { Kelompok } \\
\text { Kontrol }\end{array}$ & 64,00 & & \\
\hline
\end{tabular}

(Sumber: Analisis data Penelitian 2021)

Melihat dari hasil uji hipotesis pada tabel di atas, dengan menggunakan Uji t dua sampel Independen pada nilai posstest kedua kelompok di dapatkan nilai Sig. (Two-Sided P) yaitu sebesar 0,001, yang mana nilai Sig yang diperoleh lebih kecil dari $\alpha=0,05$. Maka peneliti dapat simpulkan uji hipotesis dalam penelitian ini yaitu menerima $\mathrm{H}_{1}$ dan menolak $\mathrm{H}_{0}$ dengan penjelasan bahwa nilai posttest pada kelompok eksperimen dan kelompok kontrol memiliki hasil nilai yang berbeda secara signifikan, yang mana proses pembelajaran menggunakan media video animasi pada kelompok eksperimen berpengaruh terhadap pemahaman konsep segitiga siswa khususnya pada kelas IV di SDN Gentramasekdas.

\section{Simpulan}

Berdasarkan pada hasil penelitian dan pengujian yang telah dilakukan dalam penelitian, didapatkan bahwa siswa yang dalam proses pembelajarannya menggunakan media video animasi memperoleh hasil belajar yang lebih tinggi dibandingkan dengan siswa yang proses pembelajarannya hanya menggunakan metode konvensional. Hal tersebut membuktikan bahwa penggunaan media video animasi memberikan pengaruh terhadap 
pemahaman konsep segitiga siswa kelas IV yang pada akhirnya akan mempengaruhi prestasi belajar siswa secara keseluruhan.

\section{Daftar Pustaka}

Hobri, Susanto, Syaifuddin, M., Maylistiyana, D. E., Hosnan, Cahyanti, A. E., \& Syahrinawati, K. A. (2019). Senang Belajar Matematika (Cetakan Ke). Kementerian Pendidikan dan Kebudayaan.

Jaksin. (2016). Metodologi Penelitian Eksperimen Bidang Pendidikan (Pertama). CV. ALVABETA.

Lestari, K. E., \& Yudhanegara, M. R. (2018). Penelitian Pendidikan Matematika (Anna (ed.); Cetakan ke). PT. Revika Aditama.

Menteri Pendidikan Nasional. (2006). Peraturan Menteri Pendidikan Nasional Nomor 22 Tahun 2006. Republik Indonesia. https://journal.unnes.ac.id/nju/index.php/k reatif/article/view/KR-16/10553

Muhtarom, Nizaruddin, \& Aryan Eka Prastya Nugraha. (2020). Pelatihan Pembuatan Media Untuk Pembelajaran Jarak Jauh. Jurnal Abdimas Bina Bangsa, 1(1), 98106. https://doi.org/10.46306/jabb.v1i1.19

Pradipta, D. A. (2018). Pengaruh Minat Belajar Dan Komunikasi Matematis Terhadap Pemahaman Konsep Matematika. EKUIVALEN - Pendidikan Matematika, 31(1), 66-71.

http://ejournal.umpwr.ac.id/index.php/ekui valen/article/view/4356
Prasetia, F. (2016). Pengaruh Media Audio Visual Terhadap Hasil Belajar Matematika. Jurnal Kajian Pendidikan Matematika, 01(02), 257-266.

Sari, F. R. (2018). Penerapan Pembelajaran Example Non Example Berbantu Video Animasi Matematika Untuk Meningkatkan Pemahaman Konsep Siswa. EKUIVALEN - Pendidikan Matematika, 31(1), 37-42. http://ejournal.umpwr.ac.id/index.php/ekui valen/article/view/4351/4051

Susanto, A. (2016). Teori Belajar dan Pembelajaran Di Sekolah Dasar (Vetakan $\mathrm{Ke})$. KENCANA.

\section{Profil Penulis}

Thya Twozia lahir di Sukabumi pada tanggal 22 Juni 1996 merupakan anak ke tiga dari empat saudara. Penulis lahir dari pasangan suami istri Bapak Ade Kandi dan Ibu Kokom Komariah. Pendidikan yang telah ditempuh penulis yaitu pendidikan dasar di SDN Gentramasekdas lulus pada tahun 2008, lalu dilanjutkan pada sekolah menengah pertama di SMP Negeri 1 Cikembar lulus pada tahun 2011, dan melanjutkan di SMK Negeri 3 Sukabumi lulus pada tahun 2014. Kemudian penulis melanjutkan jenjang pendidikan ke Universitas Muhammadiyah Sukabumi (UMMI) pada tahun 2017 sampai saat dengan penulisan karya ilmiah ini penulis masih terdaftar sebagai mahasiswa program S1 Pendidikan Guru Sekolah Dasar Universitas Muhammadiyah Sukabumi. 